\title{
Dynamic behaviors of a nonautonomous predator-prey system with Holling type II schemes and a prey refuge
}

\author{
Yumin $\mathrm{Wu}^{1 *}\left(\mathrm{D}\right.$, Fengde Chen ${ }^{2}$ and Caifeng $\mathrm{Du}^{3}$
}

"Correspondence:

wuyumin89@163.com

${ }^{1}$ School of Basic Science, Shengli

College China University of

Petroleum, Dongying, Shandong,

257061, P.R. China

Full list of author information is

available at the end of the article

\begin{abstract}
In this paper, we consider a nonautonomous predator-prey model with Holling type Il schemes and a prey refuge. By applying the comparison theorem of differential equations and constructing a suitable Lyapunov function, sufficient conditions that guarantee the permanence and global stability of the system are obtained. By applying the oscillation theory and the comparison theorem of differential equations, a set of sufficient conditions that guarantee the extinction of the predator of the system is obtained.
\end{abstract}

Keywords: Predator-prey; Permanence; Holling type II; Global stability; Refuge

\section{Introduction}

The dynamic relationship between predator and prey has long been and will continue to be one of the dominant themes in both ecology and mathematical ecology due to its universal existence and importance [1]. Furthermore, the study of dynamic behaviors of predatorprey system incorporating a prey refuge become one of the most important research topic; see [2-31]. In [2], Amant proposed a Lotka-Volterra predator-prey model with a constant prey refuge:

$$
\begin{aligned}
& \dot{x}(t)=r x-\beta(x-m) y, \\
& \dot{y}(t)=e(x-m) y-d y,
\end{aligned}
$$

where $x(t)$ and $y(t)$ denote the densities of prey and predator populations at time $t$, respectively, $r$ is the growth rate of the prey, $\beta$ is the per capita rate of predation, $m$ is the constant prey refuge, $e$ is a conversion rate of eaten prey into new predator abundance, and $d$ is the per capita death rate of the predator.

Considering there is an upper limit on how much predators can eat, the response of the predator to the bait should be a function of the saturation factor. In [3], GonzlezOlivares and Ramos-Jiliberto investigated the dynamic behaviors of predator-prey system

(c) The Author(s) 2021. This article is licensed under a Creative Commons Attribution 4.0 International License, which permits use, sharing, adaptation, distribution and reproduction in any medium or format, as long as you give appropriate credit to the original author(s) and the source, provide a link to the Creative Commons licence, and indicate if changes were made. The images or other third party material in this article are included in the article's Creative Commons licence, unless indicated otherwise in a credit line to the material. If material is not included in the article's Creative Commons licence and your intended use is not permitted by statutory regulation or exceeds the permitted use, you will need to obtain permission directly from the copyright holder. To view a copy of this licence, visit http://creativecommons.org/licenses/by/4.0/. 
incorporating Holling type II and a constant prey refuge:

$$
\begin{aligned}
& \dot{x}(t)=r x\left(1-\frac{x}{K}\right)-\frac{\beta(x-m) y}{(x-m)+a}, \\
& \dot{y}(t)=-d y+\frac{c \beta(x-m) y}{(x-m)+a},
\end{aligned}
$$

where $K$ is the prey environmental carrying capacity, $a$ is the amount of prey needed to achieve one-half of $\beta$. They show that the effect of prey refuges would have a stabilizing influence on the dynamical consequences of system (1.2).

Some scholars argued that the nonautonomous case is more realistic, because many biological or environmental parameters do subject to fluctuate with time, thus more complex equations should be introduced. Many scholars studied the dynamic behaviors of nonautonomous predator-prey system incorporating prey refuge. In [4], Zhu proposed and studied the nonautonomous predator-prey system incorporating prey refuge:

$$
\begin{aligned}
& \dot{x}(t)=x(t)[a(t)-b(t) x(t)]-c(t)(x(t)-m(t)) y(t), \\
& \dot{y}(t)=y(t)\left[-r_{1}(t)-k(t) y(t)+d(t)(x(t)-m(t))\right],
\end{aligned}
$$

where $x(t)$ and $y(t)$ denote the density of prey and predator populations at time $t$, respectively. $a(t), b(t), c(t), m(t), r_{1}(t), k(t), d(t)$ are nonnegative continuous function that have the upper and lower bounds. $a(t)$ is the intrinsic per capita growth rate of prey, $b(t)$ is the per capita death rate of prey, $c(t)$ is the maximal per capita consumption rate of predators, $m(t)$ is the maximum capacity of refuge, $r_{1}(t)$ is the per capita death rate of predator, $k(t)$ is the density constraints on predator populations, and $d(t) / c(t)$ is the conversion coefficient. In [4], the sufficient conditions to guarantee the global asymptotic stability of the system (1.3) are obtained. On the basis of system (1.3), Wu [5] further studied the extinction of predator populations. In this paper, we study the nonautonomous predator-prey system incorporating prey refuge and Holling type II schemes:

$$
\begin{aligned}
& \dot{x}(t)=x(t)[a(t)-b(t) x(t)]-\frac{c(t)(x(t)-m(t)) y(t)}{a_{1}(t)+x(t)-m(t)}, \\
& \dot{y}(t)=y(t)\left[-r_{1}(t)-k(t) y(t)+\frac{d(t)(x(t)-m(t))}{a_{1}(t)+x(t)-m(t)}\right],
\end{aligned}
$$

where $a_{1}(t)$ is the amount of prey needed to achieve one-half of $c(t)$.

Based on the biological significance of systems, we consider system (1.4) together with the following initial conditions:

$$
x(0)>0, \quad y(0)>0 .
$$

Furthermore, for a bounded continuous function $g(t)$ defined on $R$,

$$
g^{l}=\inf _{t \in R} g(t), \quad g^{u}=\sup _{t \in R} g(t) .
$$

The following work is organized as follows. Sufficient conditions which guarantee the positive and permanence of system (1.4) are given in Sect. 2. In Sect. 3, we obtained a set 
of sufficient conditions for global stability of the system (1.4). In Sect. 4, the extinction of predator are studied and a set of sufficient conditions that guarantee the extinction of predator are obtained. In Sect. 5, three examples together with their numerical simulations show the feasibility of the main results. This paper ends by a brief conclusion.

\section{Positive and permanence}

Lemma 2.1 If the system (1.4) satisfies

$$
a_{1}^{l}>m^{u}
$$

then $R_{+}^{2}=\{(x, y) \mid x>0, y>0\}$ is a invariant set of the system (1.4).

Proof Let $(x(t), y(t))^{T}$ be any positive solution of the system (1.4) that satisfies the initial condition (1.5). From the first equation of the system (1.4), it follows that

$$
\begin{aligned}
& \left.\dot{x}\right|_{x=0}=\frac{c(t) m(t) y(t)}{a_{1}(t)-m(t)}, \\
& y(t)=y(0) \exp \left\{\int_{0}^{t}\left[-r_{1}(s)-k(s) y(s)+\frac{d(s)(x(s)-m(s))}{a_{1}(s)+x(s)-m(s)}\right] d s\right\} .
\end{aligned}
$$

Therefore, Lemma 2.1 is true when the conditon $(2.1)$ is true and $x(0)>0, y(0)>0$.

Lemma 2.2 For every positive solution $(x(t), y(t))^{T}$ that satisfies the initial condition (1.5), if the system satisfies (2.1) and

$$
a^{l}>\frac{c^{u} M_{2}}{a_{1}^{l}-m^{u}} ; \quad r_{1}^{u}<\frac{d^{l}\left(m_{1}-m^{u}\right)}{a_{1}^{u}+M_{1}} ; \quad m_{1}>m^{u} .
$$

then, for every positive solution $(x(t), y(t))^{T}$ that satisfies the initial condition (1.5), system (1.4) is permanent. That is,

$$
\limsup _{t \rightarrow \infty} x(t) \leq M_{1}, \quad \limsup _{t \rightarrow \infty} y(t) \leq M_{2}, \quad \liminf _{t \rightarrow \infty} x(t) \geq m_{1}, \quad \liminf _{t \rightarrow \infty} y(t) \geq m_{2} .
$$

Here,

$$
\begin{aligned}
& M_{1}=\frac{a^{u}}{b^{l}}, \quad M_{2}=\frac{d^{u} M_{1}}{k^{l}\left(a_{1}^{l}-m^{u}\right)}, \\
& m_{1}=\frac{a^{l}\left(a_{1}^{l}-m^{u}\right)-c^{u} M_{2}}{b^{u}\left(a_{1}^{l}-m^{u}\right)}, \quad m_{2}=\frac{d^{l}\left(m_{1}-m^{u}\right)-r_{1}^{u}\left(a_{1}^{u}+M_{1}\right)}{k^{u}\left(a_{1}^{u}+M_{1}\right)} .
\end{aligned}
$$

Proof For every positive solution $(x(t), y(t))^{T}$ that satisfies the initial condition (1.5), from the first equation of system (1.4), condition (2.1) and the third condition of (2.2), it follows that

$$
\begin{aligned}
\dot{x}(t) & =x(t)[a(t)-b(t) x(t)]-\frac{c(t)(x(t)-m(t)) y(t)}{a_{1}(t)+x(t)-m(t)} \\
& \leq x(t)\left[a^{u}-b^{l} x(t)\right] .
\end{aligned}
$$


Hence, according to Lemma 2.3 in [32], it is directly found that

$$
\limsup _{t \rightarrow \infty} x(t) \leq \frac{a^{u}}{b^{l}}:=M_{1} \text {. }
$$

For any small positive constant $\varepsilon>0$, there exists $T_{1}>0$ such that, for all $t \geq T_{1}$,

$$
x(t)<M_{1}+\varepsilon .
$$

It follows from (2.5) and the second equation of the system (1.4) that

$$
\begin{aligned}
\dot{y}(t) & =y(t)\left[-r_{1}(t)-k(t) y(t)+\frac{d(t)(x(t)-m(t))}{a_{1}(t)+x(t)-m(t)}\right] \\
& \leq y(t)\left[-k(t) y(t)+\frac{d(t) x(t)}{a_{1}(t)-m(t)}\right] \\
& \leq y(t)\left[-k^{l} y(t)+\frac{d^{u}\left(M_{1}+\varepsilon\right)}{a_{1}^{l}-m^{u}}\right] .
\end{aligned}
$$

According to Lemma 2.3 in [32], it follows that

$$
\limsup _{t \rightarrow \infty} y(t) \leq \frac{d^{u}\left(M_{1}+\varepsilon\right)}{k^{l}\left(a_{1}^{l}-m^{u}\right)} .
$$

Because of the arbitrariness of $\varepsilon$, let $\varepsilon \rightarrow 0$, it follows from (2.7) that

$$
\limsup _{t \rightarrow \infty} y(t) \leq \frac{d^{u} M_{1}}{k^{l}\left(a_{1}^{l}-m^{u}\right)}:=M_{2} .
$$

Conditions (2.8) implies that, for any small $\varepsilon>0$, there exists a $T_{2}>T_{1}$, such that, for all $t>T_{2}$,

$$
y(t)<M_{2}+\varepsilon
$$

Then, for $t>T_{2}$, from the first equation of system (1.4), it follows that

$$
\begin{aligned}
\dot{x}(t) & =x(t)[a(t)-b(t) x(t)]-\frac{c(t)(x(t)-m(t)) y(t)}{a_{1}(t)+x(t)-m(t)} \\
& \geq x(t)\left[a(t)-b(t) x(t)-\frac{c(t) y(t)}{a_{1}(t)-m(t)}\right] \\
& \geq x(t)\left[a^{l}-b^{u} x(t)-\frac{c^{u}\left(M_{2}+\varepsilon\right)}{a_{1}^{l}-m^{u}}\right] .
\end{aligned}
$$

According to Lemma 2.3 in [32], it follows that

$$
\liminf _{t \rightarrow \infty} x(t) \geq \frac{a^{l}-\frac{c^{u}\left(M_{2}+\varepsilon\right)}{a_{1}^{l}-m^{u}}}{b^{u}} .
$$

Let $\varepsilon \rightarrow 0$, then

$$
\liminf _{t \rightarrow \infty} x(t) \geq \frac{a^{l}\left(a_{1}^{l}-m^{u}\right)-c^{u} M_{2}}{b^{u}\left(a_{1}^{l}-m^{u}\right)}:=m_{1} .
$$


Let $0<\varepsilon<\frac{1}{2} m_{1}$ be any positive constant small enough. Then it follows from (2.12) that there exists a $T_{3}>T_{2}$, such that, for all $t>T_{3}$,

$$
x(t)>m_{1}-\varepsilon .
$$

From the second equation of the system (1.4) together with (2.5) and (2.13), it follows

$$
\begin{aligned}
\dot{y}(t) & =y(t)\left[-r_{1}(t)-k(t) y(t)+\frac{d(t)(x(t)-m(t))}{a_{1}(t)+x(t)-m(t)}\right] \\
& \geq y(t)\left[-r_{1}(t)-k(t) y(t)+\frac{d(t)(x(t)-m(t))}{a_{1}(t)+x(t)}\right] \\
& \geq y(t)\left[-r_{1}^{u}-k^{u} y(t)+\frac{d^{l}\left(m_{1}-\varepsilon-m^{u}\right)}{a_{1}^{u}+M_{1}+\varepsilon}\right] .
\end{aligned}
$$

According to Lemma 2.3 in [32], it follows that

$$
\liminf _{t \rightarrow \infty} y(t) \geq \frac{\frac{d^{l}\left(m_{1}-\varepsilon-m^{u}\right)}{a_{1}^{u}+M_{1}+\varepsilon}-r_{1}^{u}}{k^{u}} .
$$

Let $\varepsilon \rightarrow 0$, then

$$
\liminf _{t \rightarrow \infty} y(t) \geq \frac{\frac{d^{l}\left(m_{1}-m^{u}\right)}{a_{1}^{u}+M_{1}}-r_{1}^{u}}{k^{u}}:=m_{2} .
$$

This completes the proof of Lemma 2.2.

\section{Global stability}

We introduce some notations before we state the main result of this section. Set

$$
\begin{aligned}
& \delta_{1}(t)=a_{1}(t)+x(t)-m(t), \\
& \delta_{2}(t)=a_{1}(t)+x_{1}(t)-m(t), \\
& \Delta\left(m_{1}\right)=a_{1}^{l}+\left(m_{1}-\varepsilon\right)-m^{u}, \\
& A=b^{l}-\frac{c^{u} M_{2}+d^{u} a_{1}^{u}}{\left[\Delta\left(m_{1}\right)\right]^{2}} \\
& B=k^{l}-\frac{c^{u} m^{u}}{\Delta\left(m_{1}\right) m_{1}} .
\end{aligned}
$$

Theorem 3.1 Let $(x(t), y(t))^{T},\left(x_{1}(t), y_{1}(t)\right)^{T}$ be the positive solutions of system (1.4), assume system (1.4) satisfies all the conditions of Lemma 2.2, assume further that

$$
A<0, \quad B<0,
$$

then

$$
\lim _{t \rightarrow+\infty}\left[\left|x(t)-x_{1}(t)\right|+\left|y(t)-y_{1}(t)\right|\right]=0 .
$$

That is, the system (1.4) shows global stability. 
Proof From (3.1), it follows that

$$
\Delta\left(m_{1}^{\varepsilon}\right)=a_{1}^{l}+\left(m_{1}-\varepsilon\right)-m^{u} .
$$

Let

$$
\begin{aligned}
& V_{1}(t)=\left|\ln x(t)-\ln x_{1}(t)\right|, \\
& V_{2}(t)=\left|\ln y(t)-\ln y_{1}(t)\right| .
\end{aligned}
$$

Then, for $t>T$, we have

$$
\begin{aligned}
D^{+} V_{1}(t)= & s g n\left(x(t)-x_{1}(t)\right)\left(-b(t)\left(x(t)-x_{1}(t)\right)+\frac{c(t) y_{1}(t)}{\delta_{2}(t)}-\frac{c(t) y(t)}{\delta_{1}(t)}\right. \\
& \left.+\frac{c(t) m(t) y(t)}{\delta_{1}(t) x(t)}-\frac{c(t) m(t) y_{1}(t)}{\delta_{2}(t) x_{1}(t)}\right) \\
= & s g n\left(x(t)-x_{1}(t)\right)\left(-b(t)\left(x(t)-x_{1}(t)\right)-\left(y(t)-y_{1}(t)\right) \frac{c(t)}{\delta_{1}(t)}\right. \\
& +\left(x(t)-x_{1}(t)\right) \frac{c(t) y(t)}{\delta_{1}(t) \delta_{2}(t)}+\frac{c(t) m(t)}{\delta_{1}(t) x(t)}\left(y(t)-y_{1}(t)\right) \\
& -\frac{c(t) m(t) y_{1}(t)}{\delta_{1}(t) x(t) x_{1}(t)}\left(x(t)-x_{1}(t)-\frac{c(t) m(t) y_{1}(t)}{\delta_{1}(t) \delta_{2}(t) x_{1}(t)}\left(x(t)-x_{1}(t)\right)\right) \\
= & \left(-b(t)+\frac{c(t) y(t)}{\delta_{1}(t) \delta_{2}(t)}-\frac{c(t) m(t) y_{1}(t)}{\delta_{1}(t) x(t) x_{1}(t)}-\frac{c(t) m(t) y_{1}(t)}{\delta_{1}(t) \delta_{2}(t) x_{1}(t)}\right)\left|x(t)-x_{1}(t)\right| \\
& +\left(\frac{c(t) m(t)}{\delta_{1}(t) x(t)}-\frac{c(t)}{\delta_{1}(t)}\right)\left|y(t)-y_{1}(t)\right| \\
\leq & \left(-b(t)+\frac{c(t) y(t)}{\delta_{1}(t) \delta_{2}(t)}\right)\left|x(t)-x_{1}(t)\right|+\frac{c(t) m(t)}{\delta_{1}(t) x(t)}\left|y(t)-y_{1}(t)\right| \\
\leq & \left(-b^{l}+\frac{c^{u}\left(M_{2}+\varepsilon\right)}{\left[\Delta\left(m_{1}^{\varepsilon}\right)\right]^{2}}\right)\left|x(t)-x_{1}(t)\right|+\frac{c^{u} m^{u}}{\Delta\left(m_{1}^{\varepsilon}\right)\left(m_{1}-\varepsilon\right)}\left|y(t)-y_{1}(t)\right|
\end{aligned}
$$

and

$$
\begin{aligned}
D^{+} & V_{2}(t) \\
& =\operatorname{sgn}\left(y(t)-y_{1}(t)\right)\left(-k(t)\left(y(t)-y_{1}(t)\right)+\frac{d(t)(x(t)-m(t))}{\delta_{1}(t)}-\frac{d(t)\left(x_{1}(t)-m(t)\right)}{\delta_{2}(t)}\right) \\
& =\operatorname{sgn}\left(y(t)-y_{1}(t)\right)\left(-k(t)\left(y(t)-y_{1}(t)\right)+\frac{d(t)(x(t)-m(t))}{\delta_{1}(t)}-\frac{d(t)\left(x_{1}(t)-m(t)\right)}{\delta_{2}(t)}\right) \\
& =-k(t)\left|y(t)-y_{1}(t)\right|+\frac{d(t) a_{1}(t)}{\delta_{1}(t) \delta_{2}(t)}\left|x(t)-x_{1}(t)\right| \\
& \leq-k^{l}\left|y(t)-y_{1}(t)\right|+\frac{d^{u} a_{1}^{u}}{\left[\Delta\left(m_{1}^{\varepsilon}\right)\right]^{2}}\left|x(t)-x_{1}(t)\right| .
\end{aligned}
$$

Set

$$
V(t)=V_{1}(t)+V_{2}(t) .
$$


Then

$$
\begin{aligned}
D^{+} V(t) \leq & \left(-b^{l}+\frac{c^{u}\left(M_{2}+\varepsilon\right)+d^{u} a_{1}^{u}}{\left[\Delta\left(m_{1}^{\varepsilon}\right)\right]^{2}}\right)\left|x(t)-x_{1}(t)\right| \\
& +\left(-k^{l}+\frac{c^{u} m^{u}}{\Delta\left(m_{1}^{\varepsilon}\right)\left(m_{1}-\varepsilon\right)}\right)\left|y(t)-y_{1}(t)\right| .
\end{aligned}
$$

Let $\varepsilon \rightarrow 0$, then

$$
\begin{aligned}
D^{+} V(t) & \leq\left(-b^{l}+\frac{c^{u} M_{2}+d^{u} a_{1}^{u}}{\left[\Delta\left(m_{1}\right)\right]^{2}}\right)\left|x(t)-x_{1}(t)\right|+\left(-k^{l}+\frac{c^{u} m^{u}}{\Delta\left(m_{1}\right) m_{1}}\right)\left|y(t)-y_{1}(t)\right| \\
& =-A\left|x(t)-x_{1}(t)\right|-B\left|y(t)-y_{1}(t)\right| .
\end{aligned}
$$

Here $A$ and $B$ are defined in Eq. (3.1). Setting $\alpha=\min \{A, B\}>0$. Then $(x(t), y(t))$ is stable under the meaning of Lyapunov. Integrating Eq. (3.8) from $T$ to $t$, then, for $t>T$, we get

$$
V(t)-V(T) \leq-\alpha \int_{T}^{t}\left[\left|x(s)-x_{1}(s)\right|+\left|y(s)-y_{1}(s)\right|\right] \mathrm{d} s
$$

hence,

$$
V(t)+\alpha \int_{T}^{t}\left[\left|x(s)-x_{1}(s)\right|+\left|y(s)-y_{1}(s)\right|\right] \mathrm{d} s \leq V(T)<+\infty
$$

Therefore, $V(t)$ is bounded on the interval $[T, \infty]$ and

$$
\int_{T}^{t}\left|x(s)-x_{1}(s)\right| \mathrm{d} s<+\infty, \int_{T}^{t}\left|y(s)-y_{1}(s)\right| \mathrm{d} s<+\infty .
$$

So $\left|x(t)-x_{1}(t)\right|$ and $\left|y(t)-y_{1}(t)\right|$ are integrable on the interval $[T,+\infty]$. On the other hand, it is easy to see that $\dot{x}(t), \dot{y}(t), \dot{x_{1}}(t), \dot{y_{1}}(t)$ are bounded. Therefore, $\left|x(t)-x_{1}(t)\right|$ and $\left|y(t)-y_{1}(t)\right|$ are uniformly continuous on interval $[T,+\infty]$. By the Barbalat lemma, it gives

$$
\lim _{t \rightarrow+\infty}\left[\left|x(t)-x_{1}(t)\right|+\left|y(t)-y_{1}(t)\right|\right]=0
$$

Then system (1.4) shows global stability. This completes the proof of Theorem 3.1.

\section{The extinction of predator}

Consider the following equation:

$$
\dot{x}(t)=x(t)[a(t)-b(t) x(t)]
$$

where $a(t)$ and $b(t)$ are continuous functions defined in the real domain $R$ and are bounded above and below by positive constants. From Lemma 4.1 of [33], Eq. (4.1) has a solution $x_{*}(t)$ bounded above and below by positive constants and

$$
x_{*}(t)=\left[\int_{-\infty}^{t} d(s) e^{-\int_{s}^{t} a(\tau) \mathrm{d} \tau} \mathrm{d} s\right]^{-1} .
$$


Theorem 4.1 If the system (1.4) satisfies condition (2.1) and

$$
-r_{1}^{l}+\frac{b^{u}\left(\max \left\{\frac{a^{u}}{b^{l}}, m^{u}\right\}-m^{l}\right)}{a_{1}^{l}-m^{u}}<0,
$$

then the predator population will go extinct, that is the solution of the system (1.4) satisfies

$$
\lim _{t \rightarrow \infty} y(t)=0
$$

Proof Let $(x(t), y(t))$ satisfying condition (1.5) be any positive solution of system (1.4). It is discussed in three cases.

(1) Assume that $x(t)>m(t)$ is true for all $t>0$. Let $\tilde{x}(t)$ be the solution of (4.1) with initial $\tilde{x}(0)=x(0)$. It follows from Lemma 4.1 in [33] that

$$
\lim _{t \rightarrow \infty}\left(\tilde{x}(t)-x_{*}(t)\right)=0 .
$$

Then, for any arbitrary $\varepsilon>0$, there exists a $T_{1}(>T)$, such that

$$
\left|\tilde{x}(t)-x_{*}(t)\right|<\varepsilon, \quad t \geq T_{1} .
$$

From the first equation of system (1.4), it follows that

$$
\dot{x}(t)=x(t)[a(t)-b(t) x(t)]-\frac{c(t)(x(t)-m(t))}{a_{1}(t)+x(t)-m(t)} \leq x(t)[r(t)-d(t) x(t)] .
$$

By the applying comparison theorem of differential equations, we get

$$
x(t) \leq \tilde{x}(t), \quad t \geq 0
$$

Thus, combined with (4.5), we have

$$
x(t) \leq \tilde{x}(t)=x_{*}(t)+\left(\tilde{x}(t)-x_{*}(t)\right)<x_{*}(t)+\varepsilon, \quad t \geq T_{1} .
$$

Therefore, from the second equation of system (1.4), it follows that, for $t \geq T_{1}$,

$$
\begin{aligned}
\dot{y}(t) & =y(t)\left[-r_{1}(t)-k(t) y(t)+\frac{d(t)(x(t)-m(t))}{a_{1}(t)+x(t)-m(t)}\right] \\
& \leq y(t)\left[-r_{1}(t)+\frac{d(t)\left(x_{*}(t)+\varepsilon-m(t)\right)}{a_{1}(t)-m(t)}\right] .
\end{aligned}
$$

Integrating Eq. (4.6) from $T_{1}$ to $t$, we get

$$
\begin{aligned}
y(t) & \leq y\left(T_{1}\right) e^{\int_{T_{1}}^{t}\left(-r_{1}(s)+\frac{d(s)\left(x_{*}(s)+\varepsilon-m(s)\right)}{a_{1}(s)-m(s)}\right) \mathrm{d} s} \\
& \leq y\left(T_{1}\right) e^{\int_{T_{1}}^{t}\left(-r_{1}(s)+\frac{d(s)\left(\frac{a^{u}}{\left.b^{l}+\varepsilon-m(s)\right)}\right.}{a_{1}(s)-m(s)}\right) \mathrm{d} s} \\
& \leq y\left(T_{1}\right) e^{\int_{T_{1}}^{t}\left(-r_{1}^{l}+\frac{d^{u}\left(\frac{a^{u}}{b^{l}}+\varepsilon-m^{l}\right)}{a_{1}^{l}-m^{u}}\right) \mathrm{d} s} .
\end{aligned}
$$


Let $\varepsilon \rightarrow 0$, we have

$$
y(t) \leq y\left(T_{1}\right) e^{\int_{T_{1}}^{t}\left(-r_{1}^{l}+\frac{d^{u}\left(\frac{a^{u}}{b^{l}}-m^{l}\right)}{a_{1}^{l}-m^{u}}\right) \mathrm{d} s} .
$$

Therefore, from the condition (4.3), it follows that

$$
\lim _{t \rightarrow \infty} y(t)=0 .
$$

(2) Assume that $x(t)<m(t)$ is true for all $t>0$. Then, from the second equation of system (1.4) and Lemma 2.1, it follows that

$$
\begin{aligned}
\dot{y}(t) & =y(t)\left[-r_{1}(t)-k(t) y(t)+\frac{d(t)(x(t)-m(t))}{a_{1}(t)+x(t)-m(t)}\right] \\
& \leq-k(t) y(t) .
\end{aligned}
$$

Integrating Eq. (4.8) from 0 to $t$, we get

$$
y(t) \leq y(0) e^{\int_{0}^{t}(-k(s)) \mathrm{d} s} \leq y(0) e^{-k^{l} t} .
$$

Therefore,

$$
\lim _{t \rightarrow \infty} y(t)=0
$$

(3) Assume that $x(t)$ oscillates with respect to $m(t)$. In this case, suppose $x(t)$ and $m(t)$ intersect each other at the point $t_{i}, i=0,1,2, \ldots$, and

$$
x(t)>m(t), \quad t \in\left(t_{2 k+1}, t_{2 k+2}\right) ; \quad x(t)<m(t), \quad t \in\left(t_{2 k+2}, t_{2 k+3}\right) .
$$

Now assume that $x(t)$ maximizes at the point $\tau_{k} \in\left(t_{2 k+1}, t_{2 k+2}\right), k=0,1,2, \ldots$, then $x\left(\tau_{k}\right)>$ $m\left(\tau_{k}\right)$ and $\left.\dot{x}(t)\right|_{t=\tau_{k}}=0$.

From the first equation of system (1.4), it follows that

$$
\left.\dot{x}(t)\right|_{t=\tau_{k}}=x\left(\tau_{k}\right)\left[a\left(\tau_{k}\right)-b\left(\tau_{k}\right) x\left(\tau_{k}\right)\right]-\frac{c\left(\tau_{k}\right)\left(x\left(\tau_{k}\right)-m\left(\tau_{k}\right)\right) y\left(\tau_{k}\right)}{a_{1}\left(\tau_{k}\right)+x\left(\tau_{k}\right)-m\left(\tau_{k}\right)}=0 .
$$

Then

$$
x\left(\tau_{k}\right)\left[a\left(\tau_{k}\right)-b\left(\tau_{k}\right) x\left(\tau_{k}\right)\right]>0 .
$$

By Lemma 2.1, note that $x\left(\tau_{k}\right)>0$, and combining with Eq. (4.9), $a\left(\tau_{k}\right)-b\left(\tau_{k}\right) x\left(\tau_{k}\right)>0$, that is,

$$
x\left(\tau_{k}\right)<\frac{a\left(\tau_{k}\right)}{b\left(\tau_{k}\right)} \leq \frac{a^{u}}{b^{l}} .
$$

Since $x(t)$ is maximized at the point $\tau_{k}$, the above analysis shows that $x(t)<\frac{a^{u}}{b^{l}}, t \in$ $\left(t_{2 k+1}, t_{2 k+2}\right), k=0,1,2, \ldots$ A t the same time, $x(t)<m(t)<m^{u}, t \in\left(t_{2 k+2}, t_{2 k+3}\right)$. Then, for 
all $t \geq t_{1}$,

$$
x(t)<\max \left\{\frac{a^{u}}{b^{l}}, m^{u}\right\} .
$$

Substituting Eq. (4.10) into the second formula of the system (1.4), we get, for all $t \geq t_{1}$,

$$
\begin{aligned}
\dot{y}(t) & =y(t)\left[-r_{1}(t)-k(t) y(t)+\frac{d(t)(x(t)-m(t))}{a_{1}(t)+x(t)-m(t)}\right] \\
& \leq y(t)\left[-r_{1}(t)+\frac{d(t)\left(\max \left\{\frac{a^{u}}{b^{l}}, m^{u}\right\}-m(t)\right)}{a_{1}(t)-m(t)}\right] .
\end{aligned}
$$

Integrating Eq. (4.11) from $t_{1}$ to $t$, it follows that

$$
\begin{aligned}
y(t) & \leq y\left(t_{1}\right) e^{\int_{t_{1}}^{t}\left[-r_{1}(s)+\frac{\left.d(s)\left(\max x \frac{a^{u}}{b^{l}}, m^{u}\right\}-m(s)\right)}{a_{1}(s)-m(s)}\right] \mathrm{d} s} \\
& \leq y\left(t_{1}\right) e^{\int_{t_{1}}^{t}\left[-r_{1}^{l}+\frac{d^{u}\left(\max \left\{\frac{a^{u}}{b^{l}}, m^{u}\right\}-m^{l}\right)}{a_{1}^{l}-m^{u}}\right] \mathrm{d} s} .
\end{aligned}
$$

Let $t \rightarrow \infty$, then

$$
\lim _{t \rightarrow \infty} y(t)=0
$$

This completes the proof of Theorem 4.1.

\section{Numeric simulations}

Now let us consider the following three examples.

Example 5.1

$$
\begin{aligned}
& \dot{x}(t)=x(t)[11+\cos t-3 x(t)]-\frac{5(x(t)-0.5) y(t)}{x(t)+2}, \\
& \dot{y}(t)=y(t)\left[-0.2-4 y(t)+\frac{(4+0.5 \sin t)(x(t)-0.5)}{x(t)+2}\right] .
\end{aligned}
$$

In system (5.1), corresponding to system (1.4), we assume that $a(t)=11+\cos t, b(t)=3$, $c(t)=5, m(t)=0.5, a_{1}(t)=2.5, r_{1}(t)=0.2, k(t)=4$ and $d(t)=4+0.5 \sin t$, then

$$
\begin{aligned}
& M_{1}=\frac{a^{u}}{b^{l}}=4, \quad M_{2}=\frac{d^{u} M_{1}}{k^{l}\left(a_{1}^{l}-m^{u}\right)}=2.25, \\
& m_{1}=\frac{a^{l}\left(a_{1}^{l}-m^{u}\right)-c^{u} M_{2}}{b^{u}\left(a_{1}^{l}-m^{u}\right)} \approx 1.46,
\end{aligned}
$$

and

$$
\begin{aligned}
& a_{1}^{l}-m^{u}=2>0, \quad \frac{c^{u} M_{2}}{a_{1}^{l}-m^{u}} \approx 5.625<a^{l}=10, \\
& \frac{d^{l}\left(m_{1}-m^{u}\right)}{a_{1}^{u}+M_{1}} \approx 0.21>r_{1}^{u}=0.2, \quad m_{1}=1.46>m^{u}=0.5,
\end{aligned}
$$




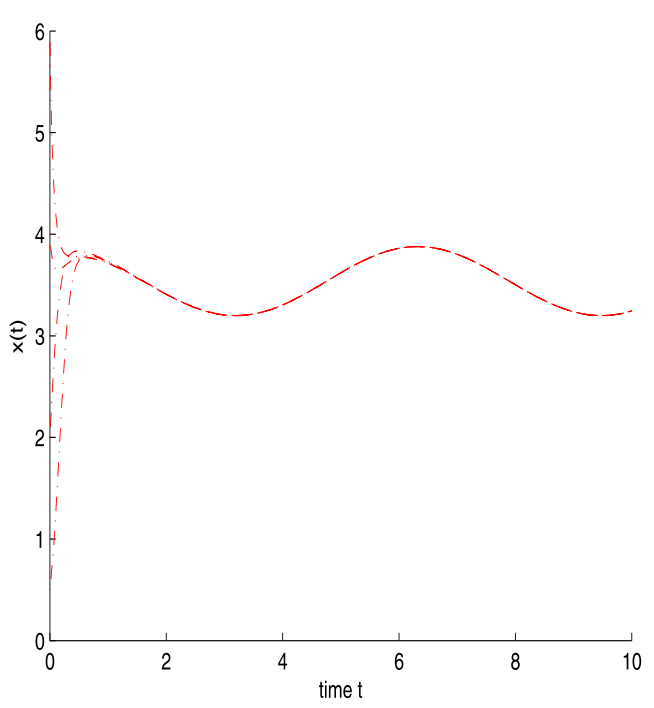

Figure 1 Dynamic behaviors of the prey population of the system (5.1), with the initial condition condition $(x(0), y(0))=(6,2),(2,0.5),(0.5,1)$ and $(4,3)$, respectively

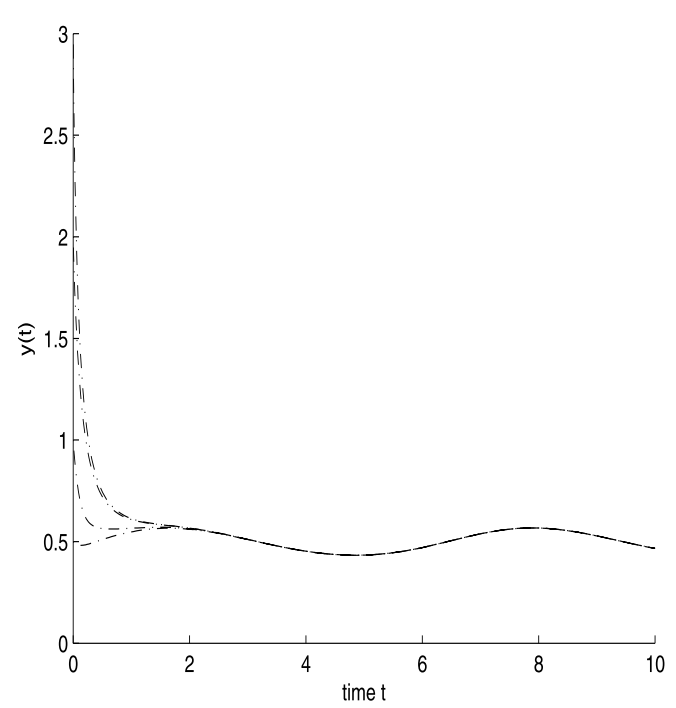

Figure 2 Dynamic behaviors of the predator population of the system (5.1), with the initial condition condition $(x(0), y(0))=(6,2),(2,0.5),(0.5,1)$ and $(4,3)$, respectively

then condition (2.1) and (2.2) are satisfied. According to Lemma 2.2, the system (1.4) is permanent. Numerical simulation (see Fig. 1 and Fig. 2) also supports this conclusion.

Example 5.2

$$
\begin{aligned}
& \dot{x}(t)=x(t)[5+\cos t-3 x(t)]-\frac{5(x(t)-2.3) y(t)}{x(t)+0.2}, \\
& \dot{y}(t)=y(t)\left[-0.2-4 y(t)+\frac{(4+0.5 \sin t)(x(t)-2.3)}{x(t)+0.2}\right] .
\end{aligned}
$$




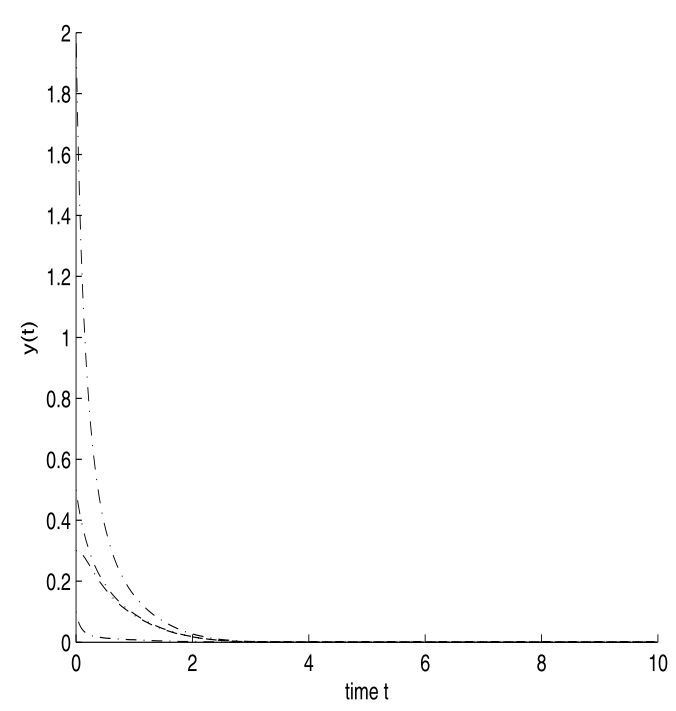

Figure 3 The extinction of the predator population of the system (5.2), with the initial condition condition $(x(0), y(0))=(6,2),(2,0.5),(0.5,0.1)$ and $(4,0.3)$, respectively

In system (5.2), corresponding to system (1.4), we assume that $a(t)=5+\cos t, b(t)=3$, $c(t)=5, m(t)=2.3, a_{1}(t)=2.5, r_{1}(t)=0.2, k(t)=4$ and $d(t)=4+0.5 \sin t$, then

$$
M_{1}=\frac{a^{u}}{b^{l}}=2
$$

and

$$
a_{1}^{l}-m^{u}=0.2>0, \quad-r_{1}^{l}+\frac{b^{u}\left(\max \left\{\frac{a^{u}}{b^{l}}, m^{u}\right\}-m^{l}\right)}{a_{1}^{l}-m^{u}}=-0.2<0
$$

then condition (2.1) and (4.3) are satisfied. According to Theorem 4.1, the predator population of system (1.4) will go extinct. Here, $m^{u}=2.3>M_{1}=2$. It follows that, when the maximum capacity of the refuge is larger than the maximum of the prey population, the predator population will go extinct. Numerical simulation (see Fig. 3) also supports this conclusion.

\section{Example 5.3}

$$
\begin{aligned}
& \dot{x}(t)=x(t)[5+\cos t-3 x(t)]-\frac{5(x(t)-1.5) y(t)}{x(t)+1}, \\
& \dot{y}(t)=y(t)\left[-1.7-4 y(t)+\frac{(4+0.5 \sin t)(x(t)-1.5)}{x(t)+1}\right] .
\end{aligned}
$$

In system (5.3), corresponding to system (1.4), we assume that $a(t)=5+\cos t, b(t)=3$, $c(t)=5, m(t)=1.5, a_{1}(t)=2.5, r_{1}(t)=1.7, k(t)=4$ and $d(t)=4+0.5 \sin t$, then

$$
M_{1}=\frac{a^{u}}{b^{l}}=2
$$




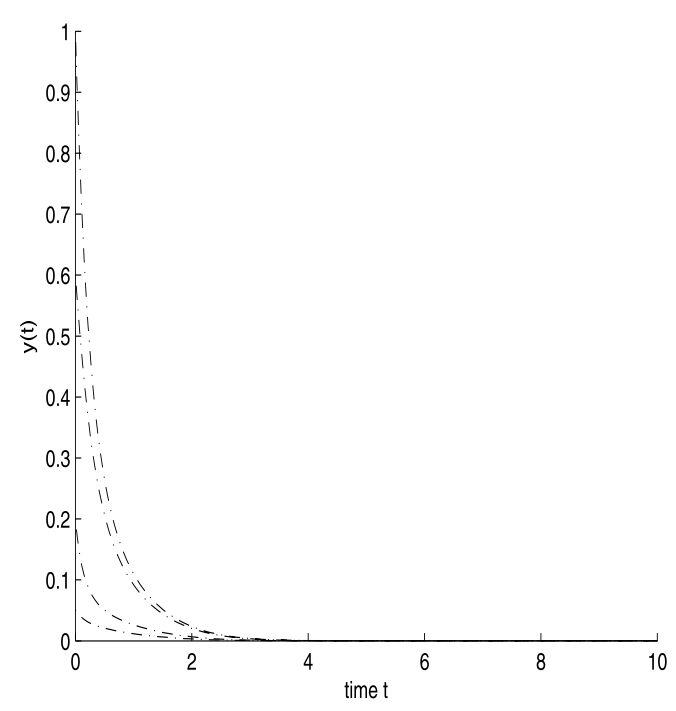

Figure 4 The extinction of the predator population of the system (5.3), with the initial condition condition $(x(0), y(0))=(6,1),(4,0.6),(0.5,0.2)$ and $(1,0.05)$ respectively

and

$$
a_{1}^{l}-m^{u}=1>0, \quad-r_{1}^{l}+\frac{b^{u}\left(\max \left\{\frac{a^{u}}{b^{l}}, m^{u}\right\}-m^{l}\right)}{a_{1}^{l}-m^{u}}=-0.2<0,
$$

then condition (2.1) and (4.3) are satisfied. According to Theorem 4.1, the predator population of system (1.4) will go extinct. Here, $m^{u}=1.5<M_{1}=2$. It follows that, when the maximum capacity of refuge is lower than the maximum of the prey population, the predator population will go extinct if the per capita death rate of predator is high enough. $\mathrm{Nu}$ merical simulation (see Fig. 4) also supports this conclusion.

\section{Conclusion}

In this paper, we consider a nonautonomous predator-prey model with Holling type II schemes and a prey refuge. Firstly, by applying the comparison theorem of differential equations, a set of conditions that ensure the permanence of the system is obtained. Secondly, by constructing a suitable Lyapunov function, sufficient conditions that guarantee the permanence and global stability of the system are investigated. Lastly, by applying the oscillation theory and the comparison theorem of differential equations, a set of sufficient conditions that guarantee the extinction of the predator of the system is obtained.

Condition (4.3) implies two situations:

(1) When the maximum capacity of refuge is larger than the maximum of the prey population, the predator population will go extinct.

(2) When the maximum capacity of refuge is lower than the maximum of the prey population, as long as per capita death rate of predator is large enough, then the predator population will go extinct. 
Funding

The research was supported by the Natural Science Foundation of Fujian Province (2019J01841).

\section{Availability of data and materials}

Data sharing not applicable to this article as no datasets were generated or analyzed during the current study.

\section{Ethics approval and consent to participate}

Not applicable.

\section{Competing interests}

The authors declare that they have no competing interests.

\section{Consent for publication}

Not applicable.

\section{Authors' contributions}

All authors contributed equally to the writing of this paper. All authors read and approved the final manuscript.

\section{Author details}

'School of Basic Science, Shengli College China University of Petroleum, Dongying, Shandong, 257061, P.R. China.

${ }^{2}$ College of Mathematics and Computer Science, Fuzhou University, Fuzhou, Fujian, 350014, P.R. China. ${ }^{3}$ Teaching Affairs Office, Shengli College China University of Petroleum, Dongying, Shandong, 257061, P.R. China.

\section{Publisher's Note}

Springer Nature remains neutral with regard to jurisdictional claims in published maps and institutional affiliations.

Received: 16 November 2020 Accepted: 6 January 2021 Published online: 21 January 2021

\section{References}

1. Berryman, A.A.: The origins and evolution of predator-prey theory. Ecology 75(5), 1530-1535 (1992)

2. González-Olivares, E., Ramos-jiliberto, R.: Dynamic consequences of prey refuges in a simple model system: more prey, fewer predators and enhanced stability. Ecol. Model. 166, 135-146 (2003)

3. Zhu, J., Liu, H.M.: Permanence of the two interacting prey-predator with refuges. J. North Univ. China Nat. Sci. 27(62), 1-3 (2006)

4. Wu, Y.M., Chen, F.D., Ma, Z.Z.: Extinction of predator species in a non-autonomous predator-prey system incorporating prey refuge. Appl. Math. J. Chin. Univ. Ser. A 27(3), 359-365 (2012)

5. Xie, X.D., Xue, Y.L., Chen, J.H., et al.: Permanence and global attractivity of a nonautonomous modified Leslie-Gower predator-prey model with Holling-type II schemes and a prey refuge. Adv. Differ. Equ. 2016, 184 (2016)

6. Yang, K., Miao, Z.S., Chen, F.D., et al.: Influence of single feedback control variable on an autonomous Holling-ll type cooperative system. J. Math. Anal. Appl. 435(1), 874-888 (2016)

7. Yue, Q.: Dynamics of a modified Leslie-Gower predator-prey model with Holling-type II schemes and a prey refuge. SpringerPlus 5(1), 1-12 (2016)

8. Ma, Z.H., Li, W.L., Zhao, Y., et al.: Effects of prey refuges on a predator-prey model with a class of functional responses. Math. Biosci. 218, 73-79 (2009)

9. Chen, L.J., Chen, F.D., Chen, L.J.: Qualitative analysis of a predator-prey model with Holling type II functional response incorporating a constant prey refuge. Nonlinear Anal., Real World Appl. 11(1), 246-252 (2010)

10. Chen, L.J., Chen, F.D.: Global stability and bifurcation of a ratio-dependent predator-prey model with prey refuge. Acta Math. Sinica (Chin. Ser.) 57, 301-310 (2014)

11. Chen, F.D., Wu, Y.M., Ma, Z.Z: Stability property for the predator-free equilibrium point of predator-prey system with a class of functional response and prey refuges. Discrete Dyn. Nat. Soc. 2012, Article ID 148942, 5 pages (2012)

12. Ma, Z.Z., Chen, F.D., Wu, C.Q., et al.: Dynamic behaviors of a Lotka-Volterra predator-prey model incorporating a prey refuge and predator mutual interference. Appl. Math. Comput. 219(15), 7945-7953 (2013)

13. Chen, F.D., Ma, Z.Z., Zhang, H.Y.: Global asymptotical stability of the positive equilibrium of the Lotka-Volterra prey-predator model incorporating a constant number of prey refuges. Nonlinear Anal., Real World Appl. 13(6), 2790-2793 (2012)

14. Jana, D.: Chaotic dynamics of a discrete predator-prey system with prey refuge. Appl. Math. Comput. 224, 848-865 (2013)

15. Liu, Z., Zhong, S.: Permanence and extinction analysis for a delayed periodic predator-prey system with Holling type II response function and diffusion. Appl. Math. Comput. 216, 3002-3015 (2010)

16. Zhu, Y., Wang, K.: Existence and global attractivity of positive periodic solutions for a predator-prey model with modified Leslie-Gower Holling-type II schemes. J. Math. Anal. Appl. 384, 400-408 (2011)

17. Kar, T.K.: Stability analysis of a prey-predator model incorporating a prey refuge. Commun. Nonlinear Sci. Numer. Simul. 10, 681-691 (2005)

18. Collings, J.B.: Bifurcation and stability analysis of a temperature dependent mite predator-prey interaction model incorporating a prey refuge. Bull. Math. Biol. 57, 63-76 (1995)

19. Abdul-Aziz, Y.: Prey dominance in discrete predator-prey systems with a prey refuge. Math. Biosci. Eng. 144, 155-178 (1997)

20. Chen, J.H.: Almost periodic solution of a nonautonomous modified Leslie-Gower predator-prey model with nonmonotonic functional response and a prey refuge. Ann. of Appl. Math. 34(1), 32-46 (2018)

21. Chow, C., Hoti, M., Li, C.M., et al.: Local stability analysis on Lotka-Volterra predator-prey models with prey refuge and harvesting. Math. Methods Appl. Sci. 41(45), 1-22 (2018) 
22. Luo, Y.T., Zhang, L., Teng, Z.D., et al.: Global stability for a nonautonomous reaction-diffusion predator-prey model with modified Leslie-Gower Holling-ll schemes and a prey refuge. Adv. Differ. Equ. 106, 1-16 (2020)

23. Wang, J., Cai, Y.L., Fu, S.M., et al.: The effect of the fear factor on the dynamics of a predator-prey model incorporating the prey refuge. Chaos 29, Article ID 083109 (2019)

24. Zhang, H.S., Cai, Y.L., Fu, S.M., et al.: Impact of the fear effect in a prey-predator model incorporating a prey refuge. Appl. Math. Comput. 356, 328-337 (2019)

25. Zhou, Y., Sun, W., Zheng, Z.G., et al.: Hopf bifurcation analysis of a predator-prey model with Holling-ll type functional response and a prey refuge. Nonlinear Dyn. 97(2), 1439-1450 (2019)

26. Chen, F.D., Lin, Q.X., Xie, X.D., et al.: Dynamic behaviors of a nonautonomous modified Leslie-Gower predator-prey model with Holling-type III schemes and a prey refuge. J. Math. Comput. Sci. 17, 266-277 (2017)

27. Xiao, Z.W., Li, Z., Zhu, Z.L., et al.: Hopf bifurcation and stability in a Beddington-DeAngelis predator-prey model with stage structure for predator and time delay incorporating prey refuge. Open Math. 17(1), 141-159 (2019)

28. Huang, X.Y., Chen, F.D.: The influence of the Allee effect on the dynamic behaviors of two species amensalism system with a refuge for the first species. Adv. Differ. Equ. 8(6), 1166-1180 (2019)

29. Huang, Y., Zhu, Z.L., Li, Z:: Modeling the Allee effect and fear effect in predator-prey system incorporating a prey refuge. Adv. Differ. Equ. 321, 1-13 (2020)

30. Khajanchi, S., Banerjee, S.: Role of constant prey refuge on stage structure predator-prey model with ratio dependent functional response. Appl. Math. Comput. 314, 193-198 (2017)

31. St. Amant, J.: The mathematics of predator-prey interactions. M.A. Thesis, Univ. of Calif., Santa Barbara, Calif. (1970)

32. Chen, F.D., Li, Z., Huang, Y.J.: Note on the permanence of a competitive system with infinite delay and feedback controls. Nonlinear Anal., Real World Appl. 8, 680-687 (2007)

33. Chen, F.D., Chen, Y.M., Shi, J.L.: Stability of the boundary solution of a nonautonomous predator-prey system with Beddington-DeAngelis functional response. J. Math. Anal. Appl. 344, 1057-1067 (2008)

\section{Submit your manuscript to a SpringerOpen ${ }^{\circ}$ journal and benefit from:}

- Convenient online submission

- Rigorous peer review

- Open access: articles freely available online

- High visibility within the field

- Retaining the copyright to your article

Submit your next manuscript at $\boldsymbol{~ s p r i n g e r o p e n . c o m ~}$ 